stage. The experience of the past few years seems more than ever to point out the futility of depending upon a large number of amateut drug raisers to supply market demands. From the standpoint of the drug manufacturer, a constant and reliable source of supply is of primary importance, and it is believed that the interests of both producers and manufacturers will be best conserved by restricting drug growing so far as possible to those individuals who are in a position to undertake the work on a permanent business basis.

\title{
FERRUM REDUCTUM.*
}

\section{BY CHARLES H. LAWALL AND J. W. E. HARRISSON.}

The standards for Ferrum Reductum were changed in the U. S. P. IX to provide for greater definiteness and accuracy, but were not made any more rigid than were the requirements of the U. S. P. VIII as regards the more important tests.

The test of greatest importance from the standpoint of the prescriber is the test for limit of sulphide.

Sulphide in reduced iron originates in the process of manufacture through the fact that the ferric oxide has not been entirely freed from soluble sulphates. These sulphates in the process of reduction are changed to sulphides and enter into combination with the iron to produce ferrous sulphide. The objectionable character of this impurity will be appreciated when it is realized that Ferrum Reductum containing larger amounts of sulphide than permitted by the U. S. P. test, will give evidence of the fact by unpleasant eructations of hydrogen sulphide when the reduced iron comes into contact with the hydrochloric acid of the gastric juices.

When the present standards were framed prior to 1914 , there was no difficulty in obtaining supplies of proposed U. S. P. quality nor was there any protest on the part of any manufacturers of inorganic chemicals, who were consulted in framing these standards, that the requirements could not be met. Shortly after the U. S. P. IX became official in I9I6, it became apparent that Ferrum Reductum of official quality was not being supplied by the manufacturers and wholesalers. Instead, an article was furnished which either bore the anomalous or misleading subterfuge "technical" so often resorted to by chemical manufacturers or it was stated on the label that "it contains sulphides in slight excess of the U. S. P. limit."

While the responsibility lies primarily with the wholesalers and manufacturers for furnishing a substandard article which is used for no other purpose than in medicine, there is also a lack of watchfulness evident on the part of the retail pharmacist who accepts and uses such an inferior article in filling prescriptions.

If every pharmacist would have returned to the manufacturer each package so labeled and would have followed this action with a vigorous protest, it would not have taken long for American chemical manufacturers to have realized their

* Read before Section on Practical Pharmacy and Dispensing, A. Ph. A., New York 
responsibility in the matter and to have taken steps to supply an article of the desired quality.

The reason given for the failure to supply an official article at the present time is that prior to the war all supplies of reduced iron came from Europe and that since that time they (the manufacturers) have been unable to obtain supplies of equal quality.

Shades of Maisch and Procter. Where is our vaunted progress in chemical manufacturing if such flimsy pretexts are to be accepted by American pharmacists for the failure to supply an article of official quality.

The real reason is that American dispensing pharmacists have supinely accepted what was sent to them without protest or question and the manufacturers have naturally taken advantage of that fact instead of maintaining a high standard of quality voluntarily.

As was the case with zinc oxide a few years ago, no improvement can probably be hoped for until some state boards make a few inspections and prosecutions and bring the entire pharmaceutical trade to a realization of its responsibilities.

The standard for sulphides is not an unnecessary nor an unattainable standard and it should be a matter of personal pride with American manufacturers to meet its requirements.

The following tabular statement shows the results of the examination of seven samples purchased in the open market representing four well known manufacturers and two wholesale druggists:

\begin{tabular}{|c|c|c|c|c|c|c|}
\hline Sample No. & 1. & 2. & 3. & 4. & 5. & $6 .{ }^{2}$ \\
\hline Ignition test..... & Normal & Normal & Normal & Normal & Normal & Abnormal \\
\hline Reaction......... & Neutral & Neutral & Neutral & Neutral & Neutral & Neutral \\
\hline Sulphides time limit. & $1 / 2 \min$. & $3^{1 / 2} \min$ & $25 \mathrm{sec}$ & I $5 \mathrm{sec}$. & Io sec. & r5 sec. \\
\hline Insoluble residue.. & Normal & Normal & Normal & Normal & Normal & $\begin{array}{l}3.3 \text { percent (ex- } \\
\text { cessive) }\end{array}$ \\
\hline $\begin{array}{l}\text { Arsenic test. } \\
\text { Assay ...... }\end{array}$ & $\begin{array}{l}\text { Normal } \\
97.1 \%\end{array}$ & $\begin{array}{l}\text { Normal } \\
89.03 \%\end{array}$ & $\begin{array}{l}\text { Normal } \\
90.65 \%\end{array}$ & $\begin{array}{l}\text { Normal } \\
99.4 \%\end{array}$ & $\begin{array}{l}\text { Normal } \\
95.05 \%\end{array}$ & $\begin{array}{l}\text { Normal } \\
90.35 \%\end{array}$ \\
\hline
\end{tabular}

An attempt was made to devise an easy and simple method for the quantitative determination of the combined sulphur but without avail.

A method in which the evolved $\mathrm{H}_{2} \mathrm{~S}$ was collected in a solution of cadmium chloride and the cadmium sulphide later determined by iodometric titration showed the amount of ferric sulphide in the samples examined to range between 0.124 and $0.40 \%$.

This is hardly sufficient to produce any adverse physiological effect but the reason for the test as previously stated is sufficiently strong to warrant its retention and the foregoing exposition of existing conditions will, it is hoped, result in immediate improvement in the quality of the article as supplied by American manufacturing chemists.

${ }^{1}$ Sample No. 6 from its physical appearance was nothing but fine iron filings. 